\title{
UTJECAJ PREDSJETVENIH TRETMANA NA KLIJANJE SJEMENA NEVENA (CALENDULA OFFICINALIS L.) PRI STRESNIM UVJETIMA
}

\author{
Monika Vidak $^{1 *}$, Anita Duvančić ${ }^{2}, Z$. Šatović ${ }^{1,2}$, Klaudija Carović-Stanko $^{1,2}$ \\ ${ }^{1}$ Znanstveni centar izvrsnosti za bioraznolikost i molekularno oplemenjivanje bilja \\ Centre of Excellence for Biodiversity and Molecular Plant Breeding (CoE CroP-BioDiv) \\ ${ }^{2}$ Zavod za sjemenarstvo, Sveučilište u Zagrebu Agronomski fakultet \\ Department of Seed Science and Technology, University of Zagreb Faculty of Agriculture
}

\section{SAŽETAK}

Neven (Calendula officinalis L.) je poznat po svojim ljekovitim svojstvima kao i primjeni u medicinskoj, kemijskoj, kozmetičkoj i prehrambenoj industriji. Prilagođen je umjerenoj klimi te mu je optimalna temperatura klijanja $20{ }^{\circ} \mathrm{C}$. Klijanje sjemena i rani rast sadnica su najosjetljiviji stadiji na abiotske stresove, kao što su nepovoljna temperatura i suša, a predsjetveni tretmani sjemena pozitivno utječu na svojstva klijavosti ili kvalitetu sjemena i sadnica u stresnim uvjetima. S obzirom da se sjetva nevena obavlja čim se uspostave minimalni uvjeti, a tada temperature $\mathrm{i}$ količine oborina mogu biti znatno niže od optimalnih, cilj ovog istraživanja bio je utvrditi utjecaj predtretmana na svojstva klijavosti sjemena nevena $\mathrm{u}$ uvjetima niskih temperatura i suše (-0,8 MPa PEG 6000). Laboratorijskim pokusom istražen je utjecaj temperature $\left(14{ }^{\circ} \mathrm{C}, 18{ }^{\circ} \mathrm{C}\right.$ i $\left.22{ }^{\circ} \mathrm{C}\right)$ na klijavost sjemena nevena uz predtretmane $\mathrm{dH}_{2} \mathrm{O}$ i GA3 (250 ppm) u trajanju od $24 \mathrm{~h}$. Netretirano sjeme je predstavljalo kontrolu. Utvrđeno je da sjeme nevena ne klije u uvjetima suše bez obzira na predsjetveni tretman i na temperaturu pri kojoj je klijalo. Ni temperatura niti predtretman sjemena ne utječu značajno na broj proklijalih sjemenki nevena, ali utječu na brzinu klijanja.

Ključne riječi: klijavost, neven, predsjetveni tretmani, suša, temperatura

\section{UVOD}

Neven (Calendula officinalis L.) je ukrasna, važna ljekovita te u novije vrijeme i uljna biljka (Król i Paszko, 2017.). Utvrđeno je da eterična ulja, karotenoidi, flavonoidi, terpeni, kumarini, masti i aminokiseline iz cvjetova nevena imaju protuupalno, antioksidativno, imunostimulirajuće, antitumorsko, antibakterijsko, antivirusno i antifungalno djelovanje (Gesch, 2013; Balenović i sur., 2018.). Neven se koristi u medicini, kemijskoj, kozmetičkoj i prehrambenoj industriji (Torbaghan, 2012; Król i Paszko, 2017.) stoga uzgoj nevena u svijetu postaje sve popularniji (Karimi i Varyani, 2016.). 
Monika Vidak i sur.: Utjecaj predsjetvenih tretmana na klijanje sjemena nevena (Calendula officinalis L.) pri stresnim uvjetima

Produktivnost biljaka u poljoprivrednim ekosustavima definirana je sjemenom, koje je najvažniji kriterij postojanja i širenja biljaka, te brzim klijanjem sjemena koje je glavni kriterij uspostave usjeva i najvažnija faza u životnom ciklusu biljaka (Bentsinka i Koornneef, 2008; Sedghi i sur., 2010.). Klijanje sjemena i rani rast sadnica su obično najosjetljiviji stadiji na abiotske stresove, uključujući ekstremne temperature (niske ili visoke), sušu ili visoku slanost (Rahimi, 2013; Jisha i sur., 2013; Fahadi sur., 2017.). Zbog klimatskih promjena, i biotski i abiotski stresovi ozbiljna su prijetnja održivosti biljne proizvodnje kao i globalnoj sigurnosti hrane (Seleiman i sur., 2021.). Temperatura je jedan od glavnih abiotskih čimbenika koji utječu na klijanje sjemena mnogih vrsta te može dovesti do odgode, smanjenja ili sprječavanja klijanja, a uz nju na klijanje sjemena utječu i drugi stresni uvjeti među kojima je suša jedan od najraširenijih (Ghaderi-Far i sur., 2010; Channaoui i sur., 2017.). Na svojstva sjemena kao što su skraćivanje vremena klijanja, harmonizacija klijanja, poboljšanje stope klijanja te poboljšanje uspostave usjeva za mnoge vrste predsjetveni tretmani sjemena imaju pozitivne učinke, posebno u nepovoljnim uvjetima kao što su niske temperature i suša (Afzal i sur., 2009; Tiryaki i Buyukcingil, 2009; Ganji-Arjenaki i sur., 2011; Yan, 2015.). S obzirom na prijašnja istraživanja na nevenu u različitim uvjetima stresa (Sedghi i sur., 2010; Akbari i sur., 2016; Karimi i Varyani, 2016.) može se pretpostaviti da različiti predsjetveni tretmani sjemena kao što su močenje sjemena u vodi (hydropriming) i pretretman hormonima (hormonalpriming) kao što je giberelinska kiselina (GA3) mogu poboljšati klijanje sjemena nevena $u$ uvjetima niskih temperatura i suše. Ovi predsjetveni tretmani potencijalno povećavaju produktivnost biljaka u stresnim uvjetima, a samim time predstavljaju uštedu na kupnji jer su potrebne manje količine sjemena zbog njegove bolje klijavosti (Kaya i sur., 2006.).

Neven je porijeklom s Mediterana i zapadne Azije (Torbaghan, 2012.) i prilagođen je umjerenoj klimi (Eberle i sur., 2014.), a optimalna temperatura za klijanje sjemena je oko $20{ }^{\circ} \mathrm{C}$ (ISTA, 1993; Koefender i sur., 2009.). Sjetva nevena se obavlja u proljeće čim to dozvole klimatske prilike, odnosno kada su zadovoljeni minimalni uvjeti za klijanje, ali tada temperatura i količina oborina u Hrvatskoj mogu biti znatno niže od optimalnih (DHMZ, 2020.). Stoga je cilj ovog istraživanja bio utvrditi utjecaj predtretmana na svojstva klijavosti [Klijavost sjemena $(G)$, Prosječno vrijeme klijanja $(M G T)$, Koeficijent varijabilnosti vremena klijanja $\left(C V_{t}\right)$, Srednja stopa klijavosti $(M R)$, Pouzdanost procesa klijanja $(U)$, Sinkronizacija procesa klijanja $(Z)$, Indeks klijavosti $(G I)$ ] sjemena nevena u uvjetima niskih temperatura i u uvjetima suše. 
Monika Vidak i sur.: Utjecaj predsjetvenih tretmana na klijanje sjemena nevena (Calendula officinalis L.) pri stresnim uvjetima

\section{MATERIJAL I METODE ISTRAŽIVANJA}

\section{Biljni materijal i predtretmani}

Istraživanje, u kojem je korišteno 1500 sjemenki ekološki proizvedenog sjemena nevena (Calendula officinalis L.) kupljenog u Lokvina d.o.o., je provedeno na Zavodu za sjemenarstvo Sveučilišta u Zagrebu Agronomski fakultet. Od 1500 sjemenki 300 je korišteno kao kontrola (T1) dok su se predtretmani sastojali od močenja 600 sjemenki 24 sata u destiliranoj vodi $\left(\mathrm{dH}_{2} \mathrm{O}\right)$ te 600 sjemenki močenih 24 sata u otopini GA3 (250 ppm). Za simulaciju stresa suše korišten je tretman s polietilen glikolom (PEG 6000) od $-0,8 \mathrm{Mpa}$.

Pokus se sastojao od ukupno 5 tretmana (Tablica 1.) pri čemu je svaki tretman bio postavljen u četiri repeticije (4 petrijeve zdjelice sa po 25 sjemenki) kako bi se usporedio utjecaj predtretmana na klijanje nevena pri tri različite temperature, $14{ }^{\circ} \mathrm{C}$, $18{ }^{\circ} \mathrm{C}$ i $22{ }^{\circ} \mathrm{C}$. Na dno petrijevih zdjelica postavljena je vata i filter papir koji su služili kao podloga za naklijavanje. Nakon postavljanja pokusa, petrijeve zdjelice su stavljene $\mathrm{u}$ komoru za naklijavanje, na konstantnu temperaturu od $14{ }^{\circ} \mathrm{C}, 18{ }^{\circ} \mathrm{C}$ i $22{ }^{\circ} \mathrm{C}, 70 \%$ vlage te režim svjetla $16 \mathrm{~h}$ dan i $8 \mathrm{~h}$ noć.

Svakih 48 sati kroz 21 dan (ISTA, 1993.) utvrđivan je broj proklijalih sjemenki, a proklijalom sjemenkom smatrala se ona kod koje je korjenčić bio veličine $\geq 2 \mathrm{~mm}$.

Tablica 1. Predtretmani i tretmani sjemena nevena

Table 1 Seed priming treatments and treatments for marigold seeds

\begin{tabular}{lll}
\hline Oznaka & Predtretmani sjemena & Tretman \\
\hline T1 & Kontrola & $\mathrm{dH}_{2} \mathrm{O}$ \\
T2 & $\mathrm{dH}_{2} \mathrm{O}$ & $\mathrm{dH}_{2} \mathrm{O}$ \\
T3 & $\mathrm{GA} 3$ & $\mathrm{dH} \mathrm{H}_{2} \mathrm{O}$ \\
T4 & $\mathrm{dH}_{2} \mathrm{O}$ & $-0,8 \mathrm{MPaPEG}$ \\
T5 & $\mathrm{GA} 3$ & $-0,8 \mathrm{MPaPEG}$ \\
\hline
\end{tabular}

dH2O - destilirana voda/distilled water, GA3 - giberelinska kiselina/gibberellic acid, PEG - polietilen glikol/polyethylene glycol

\section{Statistička obrada podataka}

Na kraju pokusa izračunata su sljedeća svojstva klijavosti:

1. Klijavost (Germinability, $G$; \%), koja predstavlja broj proklijalih sjemenki (Scott i sur., 1984.), a izračunava se prema formuli:

$$
G=\frac{\text { broj isklijalih sjemenki }}{\text { ukupan broj sjemenki }} \times 100
$$


Monika Vidak i sur.: Utjecaj predsjetvenih tretmana na klijanje sjemena nevena (Calendula officinalis L.) pri stresnim uvjetima

2. Prosječno vrijeme klijanja (Mean germination time, $M G T$; dan) se izračunava prema formuli:

$$
M G T=\frac{\sum_{i=1}^{k} n_{i} t_{i}}{\sum_{i=1}^{k} n_{i}}
$$

pri čemu $t_{i}$ označava vrijeme od početka pokusa do vremena opažanja $(i), n_{i}$ predstavlja broj proklijalih sjemenki u vremenu $(i)$, a $k$ predstavlja posljednji dan klijanja (Ranal i sur., 2009.).

3. Koeficijent varijabilnosti vremena klijanja (Coefficient of variation of the germination time, $\mathrm{CV}_{t}$; \%) se izračunava prema formuli:

$$
C V_{t}=\frac{s_{t}}{\bar{t}} 100
$$

pri čemu $s_{t}$ označava standardnu devijaciju vremena klijanja, a $\bar{t}$ prosječno vrijeme klijanja (Ranal i sur., 2009.).

4. Srednja stopa klijavosti (Mean germination rate, $M R$ ) izračunava se kao recipročna vrijednost srednjeg vremena klijanja prema formuli (Ranal i sur., 2009.):

$$
M R=1 / t
$$

5. Pouzdanost procesa klijanja (Uncertainty of the germination process, $U$ ) se izračunava prema formuli:

$$
U=-\sum_{i=1}^{k} f_{i} \log _{2} f_{i}
$$

a $f_{i}$ prema formuli :

$$
f_{i}=\frac{n_{i}}{\sum_{i=1}^{k} n_{i}}
$$

pri čemu je $f_{i}$ relativna učestalost klijanja, $n_{i}$ označava broj proklijalih sjemenki u vremenu (i), a $k$ posljednji dan opažanja (Ranal i sur., 2009.). 
Monika Vidak i sur.: Utjecaj predsjetvenih tretmana na klijanje sjemena nevena (Calendula officinalis L.) pri stresnim uvjetima

6. Ujednačenost procesa klijanja (Synchrony of the germination process, Z) se izračunava prema formuli:

$$
Z=\frac{\sum_{i=1}^{k} C_{n_{i} 2}}{C_{\sum n_{i} 2}}
$$

pri čemu je:

$$
C_{n_{i} 2}=\frac{n\left(n_{i}-1\right)}{2}
$$

te $C_{n i, 2}$ predstavlja kombinaciju sjemena klijalog dva po dva u vremenu ( $\left.i\right)$, a $n_{i}$ je broj proklijalih sjemenki u vremenu $(i)$. $Z$ predstavlja kvocijent između sume parcijalne kombinacije proklijalih sjemenki (dvije po dvije) u vremenu (i) i konačnog broja proklijalih sjemenki na kraju pokusa, pretpostavljajući da se klijanje sjemenki koje su klijale u određenom vremenu događalo simultano (Ranal i sur., 2009.).

7. Indeks klijavosti (Germination index, GI) prema formuli (Farooq i sur., 2005.):

$$
G I=\frac{\text { broj proklijalih sjemenki }}{\text { broj dana do prog prebrojavanja }}+\ldots+\frac{\text { broj proklijalih sjemenki }}{\text { broj dana do konačnog prebrojavanja }}
$$

Jednosmjerna analiza varijance provedena je u svrhu utvrđivanja značajnih razlika između tretmana za navedena svojstva. Izračun je proveden pomoću naredbe PROC GLM u programu SAS (SAS Institute, 2004.). Razlike između prosječnih vrijednosti kvantitativnih svojstava između tretmana utvrđene su pomoću Tukeyjevog testa $(\mathrm{P}<0.05)$. Izvorne vrijednosti svojstava $G$ i $C V_{t}$ izraženih u postotku su prije analize transformirane pomoću formule $\mathrm{y}=\arcsin (\mathrm{x} / 100)$.

\section{REZULTATI}

Utvrđeno je da sjeme nevena ne klije u uvjetima suše od -0,8 MPa (PEG 6000) ni nakon predtretmana sjemena te su tretmani T4 (predtretman $\mathrm{dH}_{2} \mathrm{O}$ i tretman - 0,8 MPa PEG) i T5 (predtretman GA3 i tretman - 0,8 MPa PEG) isključeni iz daljnje statističke analize zbog vrlo slabe klijavosti. Pri temperaturi od $14{ }^{\circ} \mathrm{C}$ proklijalo je samo $2 \%$ sjemenki, pri temperaturi od $18{ }^{\circ} \mathrm{C} 4 \%$ sjemenki, a pri temperaturi od $22{ }^{\circ} \mathrm{C}$ proklijalo je $12,5 \%$ sjemenki. 
Monika Vidak i sur.: Utjecaj predsjetvenih tretmana na klijanje sjemena nevena (Calendula officinalis L.) pri stresnim uvjetima

\section{Analiza varijance (ANOVA) za svojstva klijavosti sjemena nevena}

Tablicom 2. je prikazana analiza varijance za svojstva klijavosti sjemena nevena. Visoko značajna razlika između tretmana temperaturom (Temp) je utvrđena za svojstva Prosječno vrijeme klijanja $(M G T)$, Koeficijent varijabilnosti vremena klijanja $(C V t)$, Srednja stopa klijavosti $(M R)$ i Indeks klijavosti $(G I)$, a značajna razlika za svojstva Pouzdanost procesa klijanja $(U)$ i Sinkronizacija procesa klijanja $(Z)$, dok za svojstvo Klijavosti $(G)$ nije bilo statistički značajne razlike.

U interakciji temperature (Temp) i tretmana (Tr) je utvrđena visoko značajna razlika za svojstvo Indeks klijavosti $(G I)$, značajna razlika za svojstvo Klijavosti $(G)$, Koeficijent varijabilnosti vremena klijanja $\left(C V_{t}\right)$ i Srednju stopu klijavosti $(M R)$, nisko značajna razlika za svojstvo Sinkronizacija procesa klijanja $(Z)$, dok za svojstva Prosječno vrijeme klijanja $(M G T)$ i Pouzdanost procesa klijanja $(U)$ nije bilo statistički značajne razlike.

Tablica 2. Analiza varijance (ANOVA) za svojstvo klijavosti sjemena nevena

Table 2 Analysis of variance (ANOVA) for marigold seed germination characteristics

\begin{tabular}{cccccccc}
\hline $\begin{array}{c}\text { Izvor } \\
\text { varijabilnosti }\end{array}$ & $\begin{array}{c}\mathrm{G} \\
(\%)\end{array}$ & $\begin{array}{c}\mathrm{MGT} \\
(\text { dan/day })\end{array}$ & $\mathrm{CV}_{\mathrm{t}}$ & $\mathrm{MR}$ & $\mathrm{U}$ & $\mathrm{Z}$ & $\mathrm{GI}$ \\
\hline $\mathrm{Temp}$ & $\mathrm{ns}$ & $* * *$ & $* * *$ & $* * *$ & $* *$ & $* *$ & $* * *$ \\
$\mathrm{Tr}$ & $* * *$ & $* * *$ & $* * *$ & $* * *$ & $* * *$ & $* * *$ & $* * *$ \\
$\operatorname{Temp*Tr}$ & $* *$ & $\mathrm{~ns}$ & $* *$ & $* *$ & $\mathrm{~ns}$ & $*$ & $* * *$ \\
\hline
\end{tabular}

$G$ - Klijavost/Germinability; $M G T$ - Prosječno vrijeme klijanja/Mean germination time;

$M R$ - Srednja stopa klijavosti/Mean germination rate;

$C V t$ - Koeficijent varijabilnosti vremena klijanja/Coefficient of variation of the germination time;

$U$ - Pouzdanost procesa klijanja/Reliability of the germination process;

$Z$ - Sinkronizacija procesa klijanja/Synchrony of the germination process;

$G I$ - Indeks klijavosti/Germination index.

Temp - temperatura/temperature $\left(14{ }^{\circ} \mathrm{C}, 18{ }^{\circ} \mathrm{C}, 22^{\circ} \mathrm{C}\right)$;

$\mathrm{Tr}$-predtretman/priming treatment $\left(\mathrm{dH}_{2} \mathrm{O}, \mathrm{GA} 3\right)$

${ }^{\text {ns }} \mathrm{P}>0.05, * 0.05>\mathrm{P}>0.01, * * 0.01>\mathrm{P}>0.001,{ }^{*} * \mathrm{P}<0.001$

\section{Razlike izmedu temperatura za svojstva klijavosti sjemena nevena}

Post hoc testom višestruke usporedbe u parovima (Tukey) (Tablica 3.) utvrđeno je da za svojstvo Klijavosti $(G)$ nema statistički značajne razlike u odnosu na temperature (Temp $1-14{ }^{\circ} \mathrm{C}$, Temp $2-18{ }^{\circ} \mathrm{C}$, Temp $3-22{ }^{\circ} \mathrm{C}$ ) pri kojima je klijalo sjeme nevena. Za svojstva Prosječno vrijeme klijanja $(M G T)$, Srednja stopa klijavosti $(M R)$, Pouzdanost procesa klijanja $(U)$, Sinkronizacija procesa klijanja $(Z)$ i Indeks klijavosti (GI) utvrđena je statistički značajna razlika za Temp3 $\left(22{ }^{\circ} \mathrm{C}\right)$ dok je za svojstvo Koeficijent varijabilnosti vremena klijanja $\left(C V_{t}\right)$ utvrđena statistički značajna razlika za 
Monika Vidak i sur.: Utjecaj predsjetvenih tretmana na klijanje sjemena nevena (Calendula officinalis L.) pri stresnim uvjetima

Temp2 $\left(18{ }^{\circ} \mathrm{C}\right)$. Ovime je utvrđeno da temperatura nema utjecaj na broj proklijalih sjemenki nevena, ali ima utjecaj na brzinu klijanja.

Tablica 3. Razlike između temperatura za svojstva klijavosti sjemena nevena

Table 3 Differences between temperatures for marigold seed germination characteristics

\begin{tabular}{lccccccc}
\hline Temp & $\mathrm{G}(\%)$ & $\begin{array}{c}\mathrm{MGT} \\
\text { (dan/day) }\end{array}$ & $\mathrm{CV}_{\mathrm{t}}$ & $\mathrm{MR}$ & $\mathrm{U}$ & $\mathrm{Z}$ & $\mathrm{GI}$ \\
\hline Temp1 & $72,67 \mathrm{~A}$ & $3,95 \mathrm{~A}$ & $48,91 \mathrm{~B}$ & $0,27 \mathrm{~B}$ & $1,37 \mathrm{~A}$ & $0,46 \mathrm{~B}$ & $5,87 \mathrm{~B}$ \\
Temp2 & $77 \mathrm{~A}$ & $3,91 \mathrm{~A}$ & $65,00 \mathrm{~A}$ & $0,28 \mathrm{~B}$ & $1,43 \mathrm{~A}$ & $0,44 \mathrm{~B}$ & $7,00 \mathrm{~B}$ \\
Temp3 & $77 \mathrm{~A}$ & $2,83 \mathrm{~B}$ & $44,37 \mathrm{~B}$ & $0,37 \mathrm{~A}$ & $0,99 \mathrm{~B}$ & $0,61 \mathrm{~A}$ & $8,22 \mathrm{~A}$ \\
\hline
\end{tabular}

$G-$ Klijavost/Germinability;

$M G T$ - Prosječno vrijeme klijanja/Mean germination time;

$M R$ - Srednja stopa klijavosti/Mean germination rate;

$C V t$ - Koeficijent varijabilnosti vremena klijanja/Coefficient of variability of the germination time;

$U$ - Pouzdanost procesa klijanja/Reliability of the germination process;

$Z$ - Sinkronizacija procesa klijanja/Synchrony of the germination process;

GI - Indeks klijavosti/Germination index.

Temp $1-14^{\circ} \mathrm{C}$, Temp $2-18{ }^{\circ} \mathrm{C}, \mathrm{Temp} 3-22^{\circ} \mathrm{C}$.

Vrijednosti označene istim slovom značajno se ne razlikuju na temelju Tukeyjevog testa $(\mathrm{P}<0.05) /$ Values followed by the same letter in each column are not significantly different based on the Tukey test at 0.05 probability.

\section{Razlike izmedu tretmana za svojstva klijavosti sjemena nevena}

Post hoc testom višestruke usporedbe u parovima (Tukey) (Tablica 4.) utvrđeno je da se $\operatorname{Tr} 1$ (kontrola) statistički značajno razlikuje od tretmana $\operatorname{Tr} 2\left(\mathrm{dH}_{2} \mathrm{O}\right)$ i $\operatorname{Tr} 3(\mathrm{GA} 3) \mathrm{u}$ svojstvu Klijavost $(G)$.

Tablica 4. Razlike između tretmana za svojstva klijavosti sjemena nevena

Table 4 Differences between treatments for marigold seed germination characteristics

\begin{tabular}{cccccccc}
\hline $\begin{array}{c}\text { Tretman/ } \\
\text { Treatment }\end{array}$ & G (\%) & $\begin{array}{c}\text { MGT } \\
\text { (dan/day) }\end{array}$ & $\mathrm{CV}_{\mathrm{t}}$ & $\mathrm{MR}$ & $\mathrm{U}$ & $\mathrm{Z}$ & $\mathrm{GI}$ \\
\hline $\operatorname{Tr} 1$ & $84,67 \mathrm{~A}$ & $3,64 \mathrm{~B}$ & $46,78 \mathrm{~B}$ & $0,30 \mathrm{~B}$ & $1,10 \mathrm{~B}$ & $0,58 \mathrm{~A}$ & $7,33 \mathrm{~A}$ \\
$\operatorname{Tr} 2$ & $67,67 \mathrm{~B}$ & $4,40 \mathrm{~A}$ & $66,54 \mathrm{~A}$ & $0,24 \mathrm{C}$ & $1,81 \mathrm{~A}$ & $0,30 \mathrm{~B}$ & $5,67 \mathrm{~B}$ \\
$\operatorname{Tr} 3$ & $74,33 \mathrm{~B}$ & $2,64 \mathrm{C}$ & $44,96 \mathrm{~B}$ & $0,39 \mathrm{~A}$ & $0,88 \mathrm{~B}$ & $0,64 \mathrm{~A}$ & $8,09 \mathrm{~A}$ \\
\hline
\end{tabular}

$G-$ Klijavost/Germinability;

$M G T$ - Prosječno vrijeme klijanja/Meangermination time;

$M R$ - Srednja stopa klijavosti/Meangermination rate;

$C V t$ - Koeficijent varijabilnosti vremena klijanja/Coefficient of variation of the germination time;

$U$ - Pouzdanost procesa klijanja/variability of the germination process;

$Z$ - Sinkronizacija procesa klijanja/Synchrony of the germination process;

$G I$ - Indeks klijavosti/Germination index.

$\operatorname{Tr} 1$ - Kontrola/Control, Tr2 - $\mathrm{dH}_{2} \mathrm{O}, \mathrm{Tr} 3-\mathrm{GA} 3$.

Vrijednosti označene istim slovom se značajno ne razlikuju na temelju Tukeyjevog testa $(\mathrm{P}<0.05) /$ Values followed by the same letter in each column are not significantly different based on the Tukey test at 0.05 probability. 
Monika Vidak i sur.: Utjecaj predsjetvenih tretmana na klijanje sjemena nevena (Calendula officinalis L.) pri stresnim uvjetima

Za svojstva Koeficijent varijabilnosti vremena klijanja $\left(C V_{t}\right)$, Pouzdanost procesa klijanja $(U)$, Sinkronizacija procesa klijanja $(Z)$ i Indeks klijavosti $(G I) \operatorname{Tr} 2\left(\mathrm{dH}_{2} \mathrm{O}\right)$ se statistički značajno razlikuje od Tr1 (kontrola) i Tr3 (GA3), dok je za svojstva Prosječno vrijeme klijanja $(M G T)$ i Srednja stopa klijavosti $(M R)$ razlika statistički značajna za sva tri tretmana (Tr1, Tr2 i Tr3). Ovim testom je utvrđeno da tretmani nemaju utjecaj na broj proklijalih sjemenki nevena, ali imaju utjecaj na brzinu klijanja sjemena kao i na ostala svojstva.

\section{Razlike izmedu interakcija tretmana i temperatura za svojstva klijavosti sjemena nevena}

Tablicom 5. su post hoc testom višestruke usporedbe u parovima (Tukey) prikazane razlike između interakcija tretmana i temperatura za svojstva klijavosti sjemena nevena. Analizom A je utvrđeno da se značajno razlikuju interakcija Tr1*Temp3 (kontrola $+22{ }^{\circ} \mathrm{C}$ ) od interakcija Tr1*Temp1 (kontrola $+14{ }^{\circ} \mathrm{C}$ ) i Tr1*Temp2 (kontrola $+18{ }^{\circ} \mathrm{C}$ ) za svojstva Prosječno vrijeme klijanja $(M G T)$, Srednja stopa klijavosti $(M R)$ i Indeks klijavosti $(G I)$. Za svojstvo Koeficijent varijabilnosti vremena klijanja $\left(C V_{t}\right)$ značajno se razlikuju interakcije Tr1*Temp1 (kontrola $+14{ }^{\circ} \mathrm{C}$ ) od $\operatorname{Tr} 1^{*}$ Temp2 (kontrola $+18{ }^{\circ} \mathrm{C}$ ). Za svojstva Pouzdanost procesa klijanja $(U)$ i Sinkronizacija procesa klijanja $(Z)$ značajno se razlikuje interakcija $\operatorname{Tr} 1 *$ Temp2 (kontrola $+18^{\circ} \mathrm{C}$ ) od $\operatorname{Tr} 1{ }^{*}$ Temp3 (kontrola $+22^{\circ} \mathrm{C}$ ).

Tablica 5. Razlike između interakcija tretmana i temperatura za svojstva klijavosti sjemena nevena

Table 5 Differences between treatment in teractions and temperatures for marigold seed germination characteristics

\begin{tabular}{|c|c|c|c|c|c|c|c|c|}
\hline & $\begin{array}{c}\text { Tretman/ } \\
\text { Treatment } \\
\end{array}$ & $\mathrm{G}(\%)$ & $\begin{array}{c}\text { MGT } \\
\text { (dan/day) }\end{array}$ & $\mathrm{CV}_{\mathrm{t}}$ & MR & $\mathrm{U}$ & Z & GI \\
\hline \multirow{3}{*}{ A } & $\operatorname{Tr} 1 *$ Temp 1 & $82 \mathrm{AB}$ & $4,29 \mathrm{AB}$ & $27,62 \mathrm{C}$ & $0,23 \mathrm{D}$ & $1,03 \mathrm{BCD}$ & $0,61 \mathrm{AB}$ & $5,18 \mathrm{CD}$ \\
\hline & $\operatorname{Tr} 1 *$ Temp 2 & $81 \mathrm{AB}$ & $4,23 \mathrm{AB}$ & $67,35 \mathrm{AB}$ & $0,24 \mathrm{D}$ & $1,53 \mathrm{ABC}$ & $0,38 \mathrm{BCD}$ & $6,35 \mathrm{BCD}$ \\
\hline & $\operatorname{Tr} 1 *$ Temp 3 & $91 \mathrm{~A}$ & $2,41 \mathrm{CD}$ & $45,38 \mathrm{BC}$ & $0,42 \mathrm{AB}$ & $0,73 \mathrm{D}$ & $0,73 \mathrm{~A}$ & $10,45 \mathrm{~A}$ \\
\hline \multirow{3}{*}{ B } & $\operatorname{Tr} 2 *$ Temp 1 & $57 \mathrm{C}$ & $4,61 \mathrm{~A}$ & $66,50 \mathrm{AB}$ & $0,22 \mathrm{D}$ & $1,93 \mathrm{~A}$ & $0,24 \mathrm{D}$ & $4,35 \mathrm{D}$ \\
\hline & $\operatorname{Tr} 2 *$ Temp 2 & $70 \mathrm{BC}$ & $4,79 \mathrm{~A}$ & $74,56 \mathrm{~A}$ & $0,23 \mathrm{D}$ & $1,77 \mathrm{AB}$ & 0,33 CD & $5,96 \mathrm{BCD}$ \\
\hline & Tr2*Temp3 & $76 \mathrm{ABC}$ & $3,81 \mathrm{ABC}$ & $59,55 \mathrm{AB}$ & $0,26 \mathrm{CD}$ & $1,73 \mathrm{AB}$ & $0,32 \mathrm{CD}$ & $6,71 \mathrm{BCD}$ \\
\hline \multirow{3}{*}{$\mathrm{C}$} & $\operatorname{Tr} 3 *$ Temp 1 & $79 \mathrm{ABC}$ & $2,94 \mathrm{BCD}$ & $53,62 \mathrm{ABC}$ & $0,34 \mathrm{BC}$ & $1,15 \mathrm{BCD}$ & $0,52 \mathrm{ABC}$ & $8,09 \mathrm{AB}$ \\
\hline & $\operatorname{Tr} 3 *$ Temp 2 & $80 \mathrm{ABC}$ & $2,71 \mathrm{CD}$ & $53,09 \mathrm{ABC}$ & $0,37 \mathrm{AB}$ & $0,98 \mathrm{CD}$ & $0,61 \mathrm{AB}$ & $8,69 \mathrm{AB}$ \\
\hline & Tr3*Temp3 & $64 \mathrm{BC}$ & $2,26 \mathrm{D}$ & $28,17 \mathrm{C}$ & $0,44 \mathrm{~A}$ & $0,51 \mathrm{D}$ & $0,77 \mathrm{~A}$ & $7,5 \mathrm{BC}$ \\
\hline
\end{tabular}

$G-$ Klijavost/Germinability;

$M G T$ - Prosječno vrijeme klijanja/Meangermination time;

$M R$ - Srednja stopa klijavosti/Meangermination rate;

$C V t$ - Koeficijent varijabilnosti vremena klijanja/Coefficient of variation of the germination time;

$U$ - Pouzdanost procesa klijanja/variability of the germination process;

$Z$ - Sinkronizacija procesa klijanja/Synchrony of the germination process;

$G I$ - Indeks klijavosti/Germination index.

$\operatorname{Tr} 1$ - Kontrola/Control, Tr2 - $\mathrm{dH}_{2} \mathrm{O}, \operatorname{Tr} 3-\mathrm{GA} 3$; Temp $1-14^{\circ} \mathrm{C}$, Temp $2-18{ }^{\circ} \mathrm{C}, \operatorname{Temp} 3-22^{\circ} \mathrm{C}$.

Vrijednosti označene istim slovom se značajno ne razlikuju na temelju Tukeyjevog testa $(\mathrm{P}<0.05) /$ Values followed by the same letter in each column are not significantly different based on the Tukey test at 0.05 probability. 
Monika Vidak i sur.: Utjecaj predsjetvenih tretmana na klijanje sjemena nevena (Calendula officinalis L.) pri stresnim uvjetima

Analizom B je utvrđeno da nema statistički značajnih razlika između ispitivanih svojstava za interakcije tretmana i temperatura u kojima je u predtretmanu korištena destilirana voda $\left(\mathrm{dH}_{2} \mathrm{O}\right)$.

$\mathrm{U}$ analizi $\mathrm{C}$ je utvrđeno da se za svojstvo Srednja stopa klijavosti $(M R)$ značajno razlikuje $\operatorname{Tr} 3 * \operatorname{Temp} 1\left(\mathrm{GA} 3+14^{\circ} \mathrm{C}\right)$ od $\operatorname{Tr} 3 * \operatorname{Temp} 3\left(\mathrm{GA} 3+22{ }^{\circ} \mathrm{C}\right)$.

\section{RASPRAVA}

Nepovoljni uvjeti, kao što su ekstremne temperature i suša negativno utječu na klijanje, rast i produktivnost biljaka (Jisha i sur., 2013.). Za bolju uspostavu usjeva, potrebno je brzo i jednoliko nicanje sjemena, pogotovo u stresnim uvjetima (Karimi i Varyani, 2016.). U proizvodnji nevena, kao jedan od problema, javlja se loša uspostava usjeva, a predtretmani sjemena su jedan od načina koji se može koristiti za ubrzavanje rasta biljaka, posebno za ubrzavanje klijanja (Karimi i Varyani, 2016.). Ovim je istraživanjem utvrđeno da je klijavost sjemena nevena vrlo niska u uvjetima suše pri -0,8 MPa (PEG 6000) bez obzira na predtretmane sjemena što je u skladu $\mathrm{s}$ rezultatima Rashidija i Yadegarija (2014.) koji su utvrdili da je u uvjetima bez stresa (kontrola) postotak proklijalih sjemenki nevena bio $84 \%$, a u uvjetima suše pri -1 MPa samo 23\%.

Od svih okolišnih čimbenika, temperatura ima presudnu ulogu u kontroli klijanja sjemena i razvoja sadnica (Steinmaus i sur., 2000.). Prema Bewley-ju i Black-u (1994.), u sjemenu većine biljnih vrsta temperatura utječe i na kapacitet i na brzinu klijanja. Sjeme maksimalno klije na temperaturama koje se smatraju optimalnima za svaku vrstu, a temperature ispod ili iznad optimalne smanjuju brzinu procesa klijanja, što može dovesti do smanjenja ukupne klijavosti (Bewley i Black, 1994.). Ovim istraživanjem je utvrđeno da temperatura značajno utječe na sva svojstva osim na svojstvo Klijavosti $(G)$ sjemena nevena (Tablica 2.). Također je utvrđeno da se Prosječno vrijeme klijanja $(M G T)$, Srednja stopa klijavosti $(M R)$, Pouzdanost procesa klijanja $(U)$, Sinkronizacija procesa klijanja $(Z)$ i Indeks klijavosti (GI) (Tablica 3.) značajno razlikuju pri Temp3 $\left(22^{\circ} \mathrm{C}\right)$ u odnosu na Temp1 $\left(14^{\circ} \mathrm{C}\right)$ i Temp2 $\left(18^{\circ} \mathrm{C}\right)$ što znači da sjeme nevena ipak brže i ujednačenije klije pri višim temperaturama. Najviše proklijalih sjemenki (91\%) je utvrđeno u tretmanu kontrole pri temperaturi od $22{ }^{\circ} \mathrm{C}$ kao i u predtretmanu dH2O (76\%), a u predtretmanu GA3 je utvrđeno najviše proklijalih sjemenki (80\%) pri temperaturi od $18^{\circ} \mathrm{C}$.

Posljednjih godina se sve više primjenjuju predsjetveni tretmani sjemena koji su definirani kao prethodna obrada sjemena različitim metodama kako bi se poboljšala stopa klijavosti sjemena, postotak klijavosti i ujednačenost nicanja (Karimi i Varyani, 2016.). Predtretirano sjeme klije u različitim rasponima temperature (Afzal i sur., 2009.), a sadnice iznikle iz takvog sjemena pokazale su brz i jednolik rastkao i jak odgovor na abiotske stresove (Jisha i sur., 2013; Karimi i Varyani, 2016.). Ovim istraživanjem je utvrđena visoko značajna razlika između predtretmana za sva ispitivana svojstva (Tablica 2.). Utvrđeno je da se Tr1 (kontrola) statistički značajno razlikuje od 
Monika Vidak i sur.: Utjecaj predsjetvenih tretmana na klijanje sjemena nevena (Calendula officinalis L.) pri stresnim uvjetima

predtretmana $\operatorname{Tr} 2\left(\mathrm{dH}_{2} \mathrm{O}\right)$ i $\operatorname{Tr} 3(\mathrm{GA} 3)$ u svojstvu Klijavost $(G)$ (Tablica 4.), odnosno, utvrđeno je da je najviše proklijalih sjemenki nevena bilo u tretmanu Trl (kontrola). Prosječan broj proklijalih sjemenki u sve tri temperature u tretmanu Trl (kontrola) je bio 85. Predtretmani su u ovom istraživanju trajali 24 sata, a Karimi i Varyani (2016.) su utvrdili da je upotrebom predtretmana $\mathrm{GA} 3 \mathrm{i} \mathrm{dH_{2 }} \mathrm{O}$ tijekom 72 sata postotak proklijalih sjemenki nevena bio za $30 \%$ veći u usporedbi s kontrolom iako su i predtretmani u trajanju od 24 sata pokazali veću klijavost u usporedbi s kontrolom. Prema ovome se može zaključiti da je sjemenu nevena potreban predtretman trajanja dužeg od 24 sata.

Iako je najviše proklijalih sjemenki bilo u kontroli za sve tri temperature $(82 \%$ $14{ }^{\circ} \mathrm{C}, 81 \%-18{ }^{\circ} \mathrm{C}, 91 \%-22{ }^{\circ} \mathrm{C}$ ), u predtretmanu GA3 je pri temperaturi od $14{ }^{\circ} \mathrm{C}$ proklijalo $79 \%$, pri $18{ }^{\circ} \mathrm{C} 80 \%$ sjemenki, a pri $22{ }^{\circ} \mathrm{C} 64 \%$ sjemenke te rezultati ovog istraživanja upućuju na pozitivan učinak GA3 na klijanje sjemena nevena pri nižim temperaturama s obzirom da su Eberle i sur. (2014.) utvrdili da se klijanje sjemena nevena bez predtretmanana $16^{\circ} \mathrm{C}$ smanji za $50 \%$.

Iako je najviše proklijalih sjemenki u konačnici bilo u kontroli ( $\operatorname{Tr} 1)$, ovim istraživanjem je utvrđeno da sjeme nevena brže proklije ako je tretirano $\mathrm{s} \mathrm{dH}_{2} \mathrm{O}(\mathrm{Tr} 2) \mathrm{i}$ GA3 (Tr3), pogotovo pri nižim temperaturama, u odnosu na kontrolu $(\operatorname{Tr} 1)$. Tako je drugi dan brojenja proklijalih sjemenki nevena pri temperaturi od $14{ }^{\circ} \mathrm{C}$ u kontroli $(\operatorname{Tr} 1)$ bilo $6 \%$, u predtretmanu $\mathrm{dH}_{2} \mathrm{O}(\mathrm{Tr} 2) 21 \%$, a u predtretmanu GA3 (Tr3) 54\%. Pri temperaturi od $18{ }^{\circ} \mathrm{C}$ drugi dan brojenja proklijalo je $27 \%$ (kontrola, $\left.\operatorname{Tr} 1\right), 36 \%\left(\mathrm{dH}_{2} \mathrm{O}\right.$, $\operatorname{Tr} 2)$ i $62 \%$ (GA3, Tr3) sjemenki nevena, dok je pri temperaturi od $22{ }^{\circ} \mathrm{C}$ najviše proklijalih sjemenki bilo u kontroli (Tr1) (78\%), 40\% sjemenki u predtretmanu $\mathrm{dH}_{2} \mathrm{O}$ (Tr2) i 56\% u predtretmanu GA3 (Tr3). Za svojstvo Prosječno vrijeme klijanja (MGT) ovim je istraživanjem utvrđena statistički značajna razlika za sva tri tretmana. Također je utvrđeno, iako bez statističke značajnosti, da korišteni predtretmani $\left(\mathrm{dH}_{2} \mathrm{O}\right.$ i GA3) sjemena utječu na brzinu klijanja sjemena nevena pri temperaturama nižim od optimalne, a jedna od svrha predtretmana je smanjenje vremena nicanja sjemena te se predtretmani često koriste za ujednačeno i brže nicanje ljekovitog bilja i drugih ekonomski važnih biljaka (Sedghi i sur., 2010.). Jolyi sur. (2013.) su utvrdili da je smanjena klijavost pri nižim temperaturama od optimalnih najvjerojatnije posljedica odgode u klijanju dok su Savaedi i sur. (2019.) utvrdili da je najbolja i najbrža klijavost sjemena Nigella sativa L. bila nakon predtretmana s GA3, a pri temperaturama od 16 do $18^{\circ} \mathrm{C}$.

\section{ZAKLJUČAK}

Iako se u literaturi predsjetveni tretmani sjemena navode kao nužni za postizanje većeg postotka proklijalih sjemenki, u ovom istraživanju to nije bio slučaj. Naime, na temelju rezultata ovog istraživanja može se zaključiti kako je neven vrsta koja se može sijati u uvjetima nižih temperatura $\left(14^{\circ} \mathrm{C}\right.$ i $\left.18{ }^{\circ} \mathrm{C}\right)$ od optimalne pri čemu predtretmani 
Monika Vidak i sur.: Utjecaj predsjetvenih tretmana na klijanje sjemena nevena (Calendula officinalis L.) pri stresnim uvjetima

sjemena s GA3 i $\mathrm{dH}_{2} \mathrm{O}$ pridonose bržem klijanju sjemena i samim time boljem uspostavljanju usjeva, ali ne i većem postotku proklijalih sjemenki.

\section{INFLUENCE OF SEED PRIMING ON GERMINATION \\ OF MARIGOLD (CALENDULA OFFICINALIS L.) IN STRESS CONDITIONS}

SUMMARY

Marigold (Calendula officinalis L.) is known for its medicinal properties and is used in the medical, chemical, cosmetic, and food industries. It is adapted to a temperate climate and its optimum germination temperature is $20{ }^{\circ} \mathrm{C}$. Seed germination and early seedling growth are the most sensitive to abiotic stresses such as unfavourable temperatures and drought, while seed priming has a positive effect on germination properties of seed and seedling quality under stress fulconditions. Since sowing of marigolds is done as soon as the minimum conditions are established, when temperatures and precipitation can be significantly lower than optimal, the aim of this study was to determine the impact of seed priming on the germination properties of marigold seeds under low temperature and drought (-0.8 MPa PEG 6000). The effect of temperature $\left(14^{\circ} \mathrm{C}, 18{ }^{\circ} \mathrm{C}\right.$, and $\left.22{ }^{\circ} \mathrm{C}\right)$ on germination of marigold seeds with treatments containing $\mathrm{dH}_{2} \mathrm{O}$ and $\mathrm{GA} 3(250 \mathrm{ppm})$ for $24 \mathrm{~h}$ was studied under laboratory conditions. Untreated seed represented control. Marigold seeds did not germinate under drought conditions, regardless of seed priming treatments and temperatures. It was also found that neither temperature nor seed priming significantly affected the number of germinated marigold seeds, but did affect the germination rate.

Keywords: drought, gemination, marigold, seed priming, temperature

\section{LITERATURA- REFERENCES}

1. Afzal I., Ashraf S., Qasim M., Basra S.M.A., Shahid M. (2009.): Does halopriming improve germination and seedling vigour in marigold (Tagetes spp.). Seed Sci. Technol., 37: 436445 .

2. Akbari M., Yadegari M., Hamedi B. (2016.): Effect of priming on seed germination characteristics and fatty acids content in marigold (Calendula officinalis L.) seeds under UV stress and temperature. Iran. J. Seed Sci. Res., 6 (2): 203-214.

3. Balenović M., Savić V., Janječić Z., Popović M., Šimpraga B., Carović-Stanko K., Bedeković D., Amšel Zelenika T. (2018.): Immunomodulatory and antimicrobial effects of selected herbs on laying hens. Vet Arh, 88 (5): 673-686. 
Monika Vidak i sur.: Utjecaj predsjetvenih tretmana na klijanje sjemena nevena (Calendula officinalis L.) pri stresnim uvjetima

4. Bentsinka L., Koornneef M. (2008.): Seed Dormancy and Germination. U: The arabidopsis book, 6: e0119.

5. Bewley J.D., Black, M. (1994.): Seeds Physiology of Development and Germination. Plenum Press, New York.

6. Channaoui S., El Kahkahi R., Charafi J., Mazouz H., El Fechtali M., Nabloussi A. (2017.): Germination and Seedling Growth of a Set of Rapeseed (Brassica napus) Varieties under Drought Stress Conditions. IJEAB, 2 (1): 487-494.

7. Državni hidrometeorološki zavod (DHMZ) (2020.): http://meteo.hr/

8. Eberle C. A., Forcella F., Gesch R., Peterson D., Eklund J. (2014.): Seed germination of calendula in response to temperature. Ind Crops Prod., 52: 199-204.

9. Fahad S., Bajwa A.A., Nazir U., Anjum S.A., Farooq A., Zohaib A., Sadia S., Nasim W., Adkins S., Saud S., Ihsan M.Z., Alharby H., Wu C., Wang D., Huang J. (2017.): Crop Production under Drought and Heat Stress: Plant Responses and Management Options. Front. Plant Sci., 8: 1147.

10. Farooq M., Basra S.M.A., Ahmad N., Hafeez K. (2005.): Thermal Hardening: A new seed vigor enhancement tool in rice. J. Integr. Plant Biol., 47 (2): 187-193.

11. Ganji-Arjenaki F., Amini-Dehghani M., Jabbari R. (2011.): Effects of priming on seed germination of Marigold (Calendula Officinalis). Adv. Environ. Biol., 5 (2): 276-280.

12. Gesch R.W. (2013.): Growth and yield response of calendula (Calendula officinalis) to sowing date in the northern U.S. Ind Crops Prod., 45: 248-252.

13. Ghaderi-Far F., Gherekhloo J., Alimagham M. (2010.): Influence of environmental factors on seed germination and seedling emergence of yellow sweet clover (Melilotus officinalis). Planta Daninha, 28 (3): 463-469.

14. ISTA (1993.): International Rules for Seed Testing. International Seed Testing Association, Zürich, Switzerland.

15. Jisha K.C., Vijayakumari K., Puthur J.T. (2013.): Seed priming for abiotic stress tolerance: an overview. Acta Physiol Plant, 35:1381-1396.

16. Joly R., Forcella F., Peterson D., Eklund J. (2013.): Planting depth for oilseed calendula. Ind Crops Prod., 42: 133-136.

17. Karimi M., Varyani M. (2016.): Role of priming technique in germination parameters of calendula (Calendula officinalis L.) seeds. J. Agric. Sci., 61 (3): 215-226.

18. Kaya M.D., Okçu G., Atak M., Çıkılı Y., Kolsarıcı Ö. (2006.): Seed treatments to overcome salt and drought stress during germination in sunflower (Helianthus annuus L.). Europ. J. Agronomy, 24: 291-295.

19. Koefender J., Menezes N.L., Buriol G.A., Trentin R., Castilhos G. (2009.): Influênciada temperatura e da luz na germinac, ão da semente de calendula. Hortic. Bras., 27: 207210.

20. Król B., Paszko T. (2017.): Harvest date as a factor affecting crop yield, oil content and fatty acid composition of the seeds of calendula (Calendula officinalis L.) cultivars. Ind Crops Prod., 97: 242-251.

21. Rahimi A. (2013.): Seed priming improves the germination performance of cumin (Cuminum syminum L.) under temperature and water stress. Ind Crops Prod., 42: 454-460.

22. Ranal M.A., Santana D.G., Ferreira W.R., Mendes-Rodrigues C. (2009.): Calculating germination measurements and organizing spreadsheets. Rev Bras Bot, 32 (4): 849-855.

23. Rashidi M., Yadegari M. (2014.): The effect of Salinity and Drought Stress on Seed Germination, Seedling Growth and Biochemical Changes in Marigold. Adv. Environ. Biol., 8 (21): 510-515.

24. SAS Institute (2004). SAS/STAT ${ }^{\circledR} 9.1$ User's Guide. SAS Institute Inc., Cary, NC.

25. Savaedi Z., Parmoon G., Moosavi S.A., Bakhshande A. (2019.): The role of light and Gibberellic Acid on cardinal temperatures and thermal time required for germination of Charnushka (Nigella sativa) seed. Ind Crops Prod., 132: 140-149.

26. Scott S.J., Jones R.A., Williams W.A. (1984.): Review of Data Analysis Methods for Seed Germination. Crop Sci., 24 (6): 1992.

27. Sedghi M., Nemati A., Esmaielpour B. (2010.): Effect of seed priming on germination and seedling growth of two medicinal plants under salinity. Emir. J. Food Agric., 22 (2): 130-139. 
Monika Vidak i sur.: Utjecaj predsjetvenih tretmana na klijanje sjemena nevena (Calendula officinalis L.) pri stresnim uvjetima

28. Seleiman M.F., Al-Suhaibani N., Ali N., Akmal M., Alotaibi M., Refay Y., Dindaroglu T., Abdul-Wajid H.H., Battaglia M.L. (2021.): Drought Stress Impacts on Plants and Different Approaches to Alleviate Its Adverse Effects. Plants, 10: 259.

29. Steinmaus S.J., Prather T.S., Holt J.S. (2000.): Estimation of base temperatures for nine weed species. J. Exp. Bot., 51 (343): 275-286.

30. Tiryaki I., Buyukcingil Y. (2009.): Seed priming combined with plant hormones: influence on germination and seedling emergence of sorghum at low temperature. Seed Sci. Technol., 37: $303-$ 315 .

31. Torbaghan M.E. (2012.): Effect of salt stress on germination and some growth parameters of marigold (Calendula officinalis L.). Plant Sci. J., 1(1): 07-19.

32. Yan M. (2015.): Seed priming stimulate germination and early seedling growth of Chinese cabbage under drought stress. S. Afr. J. Bot., 99: 88-92.

Adrese autora - Authors adresses:

Dr.sc. MonikaVidak*e-mail: mvidak@agr.hr

Znanstveni centar izvrsnosti za bioraznolikost

i molekularno oplemenjivanje bilja,

Svetošimunska cesta 25, 10000 Zagreb

Anita Duvančić

Sveučilište u Zagrebu Agronomski fakultet,

Svetošimunska cesta 25,10000 Zagreb

Prof.dr.sc. Zlatko Šatović, e-mail: zsatovic@agr.hr

Izv. prof. dr. sc. Klaudija Carović-Stanko, e-mail: kcarovic@agr.hr

Sveučilište u Zagrebu Agronomski fakultet,

Znanstveni centar izvrsnosti za bioraznolikost

i molekularno oplemenjivanje bilja,

Svetošimunska cesta 25,10000 Zagreb.
Primljeno- Received:

16.02.2021. 
